\title{
Uncertainty assessment of the breath methane concentration method to determine methane production of dairy cows
}

\author{
Liansun $\mathbf{W u},{ }^{* 1}$ Peter W. G. Groot Koerkamp, ${ }^{*} \dagger$ and Nico Ogink ${ }^{*} \dagger$ \\ *Farm Technology Group, Wageningen University, PO Box 16, 6700 AA, Wageningen, the Netherlands \\ †Wageningen Livestock Research, PO Box 135, 6700 AC, Wageningen, the Netherlands
}

\begin{abstract}
The breath methane concentration method uses the methane concentrations in the cow's breath during feed bin visits as a proxy for the methane production rate. The objective of this study was to assess the uncertainty of a breath methane concentration method in a feeder and its capability to measure and rank cows' methane production. A range of controlled methane fluxes from a so-called artificial reference cow were dosed in a feed bin, and its exhaled air was sampled by a tube inside the feeder and analyzed. The artificial reference cow simulates the lungs, respiratory tract, and rumen of a cow and releases a variable methane flux to generate a concentration pattern in the exhaled breath that closely resembles a real cow's pattern. The strength of the relation between the controlled methane release rates of the artificial reference cow and the measured methane concentrations was analyzed by linear regression, using the coefficient of determination $\left(\mathrm{R}^{2}\right)$ and the residual standard error as performance indicators. The effect of error sources (source-sampling distance, air turbulence, and cow's head movement) on this relation was experimentally investigated, both under laboratory and barn conditions. From the laboratory to the dairy barn at the $30-\mathrm{cm}$ sampling distance, the $\mathrm{R}^{2}$-value decreased from 0.97 to 0.37 and the residual standard error increased from 75 to $86 \mathrm{ppm}$ as a result of barn air turbulence, the latter increasing to a theoretical $94 \mathrm{ppm}$ if modeled variability due to cow's head movement was accounted for as well. In practice, the effect of these random errors can be compensated by sampling strategies including repeated measurements on each cow over time, thus increasing the distinctive power between cows. However, systematic errors that may disturb the relation between concentration and production rate, such as cow variation in air exhalation rate and air flow patterns around sampling locations that differ between barns, cannot be compensated by repeated measurements. As a re-
\end{abstract}

Received February 10, 2017.

Accepted September 24, 2017.

${ }^{1}$ Corresponding author: liansun.wu@qq.com sult, the methane concentrations of breath air will vary between cows with the same methane production. We conclude that the capability of the breath concentration measurement method to adequately measure and rank methane production rates among cows is highly uncertain and requires further investigation into variation sources with a systematic nature.

Key words: methane, dairy cow, breath measurement, measurement error

\section{INTRODUCTION}

Enteric methane produced by dairy cows has become a global concern because these emissions account for $4 \%( \pm 26 \%)$ of anthropogenic greenhouse gas emissions (Gerber et al., 2013). Enteric methane from dairy cows can be mitigated through nutritional manipulations or breeding animals with lower methane production (Cottle et al., 2011). To assess the effects of these mitigation strategies, breath methane concentration (BMC) or so-called sniffer methods have been developed to assess the methane production of dairy cows at commercial farms. These methods use a gas sampling tube from the front of a cow's head to a gas analyzer to continuously analyze methane concentrations in the cow's breath when they are milked in a milking robot or visit a feed station (Garnsworthy et al., 2012; Lassen et al., 2012; Bell et al., 2014). Measured BMC is then processed to determine the cow's daily methane production rate. However, it can be questioned if a cow's actual methane production, a flux calculated as the product of concentration and transporting air volume, can be adequately represented by concentration only. Although Garnsworthy et al. (2012) found a good relation between methane production rates measured by the BMC method and in respiration chambers, Huhtanen et al. (2015) observed a weak relation between methane concentration measured by the BMC method and methane flux measured by the GreenFeed. The strength of the relation between measured BMC and the actual methane production depends on 2 different aspects.

The first aspect is animal related and deals with the relation between methane production rate and $\mathrm{BMC}$ 
at the point where it leaves the animal's mouth/nose area (further called exhalation point). If the associated air volume rate that transports the methane out of the animal is constant among cows, then variability in methane production will be directly reflected by the variability of methane concentration at the animal's exhalation point. Variability in air exhalation rates of individual cows, however, can be expected to affect the methane concentration at the exhalation point. The cow's inhalation and exhalation air mixes with methane emitted in the lungs and with the methane eructating from the rumen in the cow's respiratory tract, and the air exhalation volume thus is an important factor in transporting and emitting the methane. A higher air exhalation rate therefore will lead to stronger dilutions of the methane flux from the rumen, causing lower $\mathrm{BMC}$ at the exhalation point.

The second aspect is to which extent the animal's breath after exhalation is diluted with barn air at the sampling point. A high dilution variability weakens the relation between measured concentration at the sampling point and the true methane concentration at its exhalation point. The dilution of emitted methane from the exhalation point can be affected by several factors: the airflow pattern around the cow, the distance between exhalation and sampling point, and the cow's head movement in the feeder. Existing variable airflow in dairy barns (Joo et al., 2015; Wu et al., 2016) mixes with and dilutes the cow's emitted methane in breath. Huhtanen et al. (2015) observed a significant decrease and variation of measured concentrations by the BMC method in the laboratory with a model cow head when sampling distance changed from 0 to $30 \mathrm{~cm}$, moving the head, or introducing wind through the feed bin. Therefore, the sampling distances influence the dilution rate and cause variations in measured BMC.

Consequently, the measured BMC is a vulnerable index in determining methane production. The effects of (turbulent) aerial flow conditions, positioning of sampling point, real cow's head movement, and especially the air exhalation rate on measured $\mathrm{BMC}$, still require further research. Therefore, the objective of this study was to (1) assess the uncertainty of a BMC method under laboratory and barn conditions, and (2) its capability to measure and rank cows' methane production.

\section{MATERIALS AND METHODS}

\section{Assessment of the Breath Methane Concentration Measurement in the Laboratory}

To assess the performance of the breath methane measurement method, we first tested the method with a so-called artificial reference cow (ARC) in the air quality laboratory of Wageningen Livestock Research. The ARC is a device developed to release a variable methane flux and concentration pattern in time from a nose piece. The changes in methane flux and concentration pattern simulate methane release from lungs and eructation. The ARC precisely controls the released methane flux and concentrations at preset values to closely resemble a real cow's pattern. The ARC is made of a cylinder in which a piston inhales and exhales air with a controlled tidal volume, piston frequency, and temperature, and in which a mass flow controller doses methane from a gas cylinder. The mixed air is transported by the piston movement through a tube to a nose piece. A detailed description of this system and tests of its accuracy is given by Wu et al. (2015). The ARC's nose was placed into a model feed bin with the same dimensions and shape as the actual bins that cows use in a milking robot (Figure 1). The feed bin was made of cardboard $(60.5 \mathrm{~cm} \times 46.0 \mathrm{~cm} \times 29.0 \mathrm{~cm})$ and was partially enclosed. The inlet of the sampling tube was positioned 5 and $30 \mathrm{~cm}$ away from the ARC's nose. Air from the inlet point in the bin was continuously sampled at a rate of $4 \mathrm{~L} / \mathrm{min}$ and analyzed by a Fourier transform infrared spectroscopy gas analyzer (GASMET DX-4000, Gasmet Technologies Oy, Helsinki, Finland; calibrated according to factory instructions in the range of $0-3,000 \mathrm{ppm}$ ) giving one gas concentration value per 2 or $3 \mathrm{~s}$. In addition, a 3 -dimensional anemometer (WindMaster, Gill Instruments, UK) was placed next to the feed bin to measure air velocity outside the bin every second during the experiment.

At the start of the experiment, the ARC was run without injecting methane until the breath air had warmed up to the desired temperature of about $25^{\circ} \mathrm{C}$. At the 5-cm sampling distance (Figure 1), the ARC simulated 5 different cows with controlled methane release rates from 200 to $400 \mathrm{~g} / \mathrm{d}$, with increments of $50 \mathrm{~g} / \mathrm{d}$. Each flux level was sampled during $3.6 \mathrm{~min}$, denoted as one measurement. The measurement for each simulated cow was repeated 5 times in randomized order. The tidal volume and breath frequency of each simulated cow were controlled at $4.4 \mathrm{~L}$ and 30 times per minute.

At the 30-cm sampling distance, which was assumed to be the standard distance used in the feed bin of a milking robot, the ARC simulated 11 different cows with controlled methane release rates from 200 to 400 $\mathrm{g} / \mathrm{d}$ with increments of $20 \mathrm{~g} / \mathrm{d}$. The tidal volume and breath frequency of each simulated cow were controlled at $4.4 \mathrm{~L}$ and 30 times per minute. Each simulated flux was released during 5 min, a time interval that a cow is assumed to spend in the milking robot, and this interval was denoted as one measurement. The measurement for each simulated cow was repeated 4 times. In addition, 


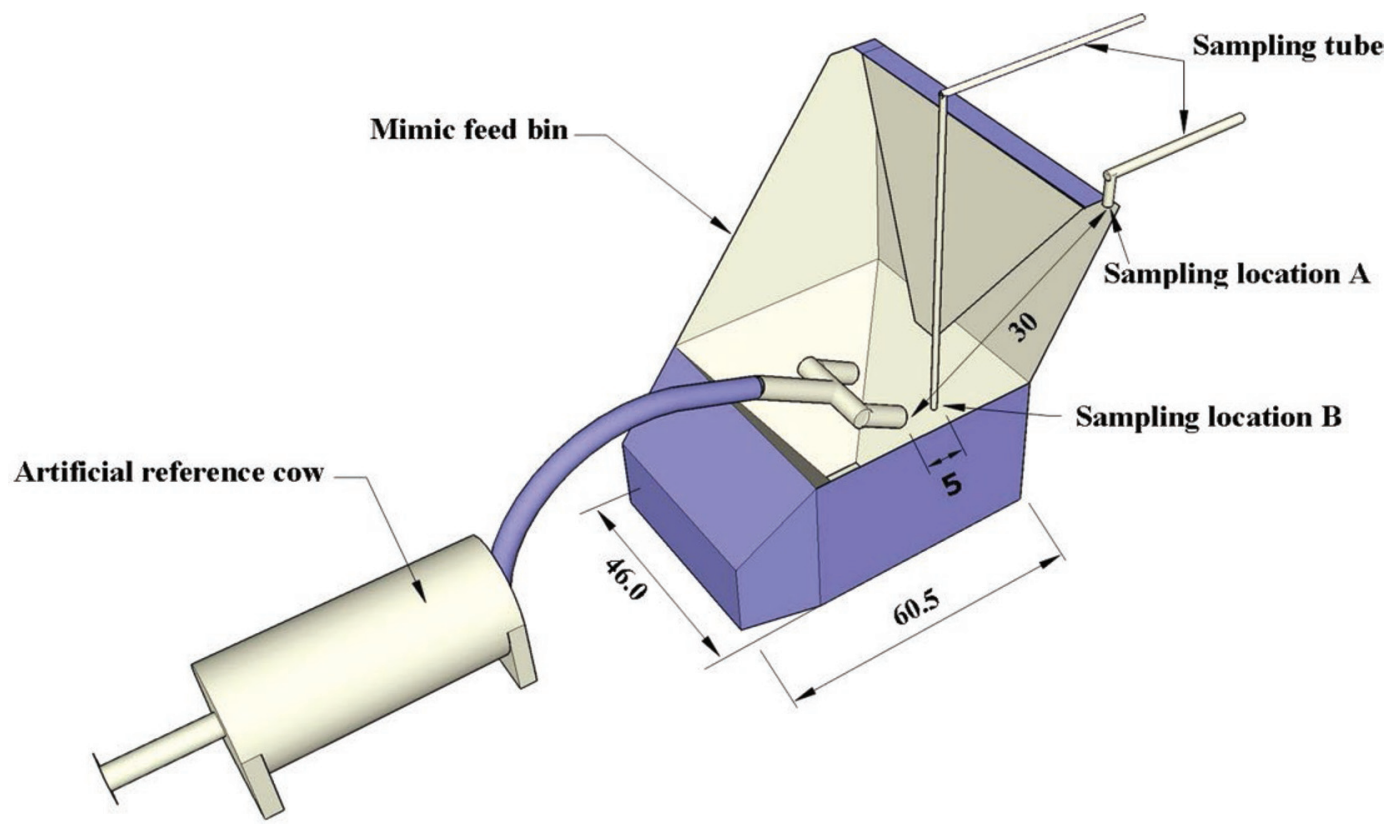

Figure 1. Schematic overview of the experimental setup in the laboratory. Sampling location A was $30 \mathrm{~cm}$ away from the artificial reference cow's nose. Sampling location B was $5 \mathrm{~cm}$ away from the artificial reference cow's nose. The feed bin's right side is removed in the figure to show the sampling locations. Color version available online.

a 10-min interval was taken between every 2 measurements to ensure that methane released into the feed bin from the previous measurement was completely cleared.

\section{Assessment of the Breath Methane Concentration Measurement in the Barn}

After analyzing BMC measurements in the laboratory under rather stable aerial conditions, we assessed the method in a dairy barn under practical conditions. This experiment was carried out in a dairy cow barn in Lelystad, the Netherlands. The dairy cow barn was equipped with a natural ventilation system that included large openings in the side walls and slatted floors in the cow area with manure storage below. The area of the openings in the side walls was automatically adjusted by curtains based on the barn temperature. Manure on the slatted floor was scraped once a day. The barn was divided into 4 areas. Each area had one milking robot serving about 60 cows. Cows were free to enter the milking robot, but were milked no more than twice a day.

We selected one milking robot to assess the BMC method with the ARC. We used a dummy cow in the milking robot to represent a cow's body to incorporate its effect on the aerial conditions. The dummy cow (220 $\mathrm{cm} \times 65 \mathrm{~cm} \times 140 \mathrm{~cm}$ ) consisted of a cow's head, body, and 4 legs, and was divided into these 3 parts for ease of handling. The ARC's nose was placed in the feed bin under the dummy cow's head. The inlet of the sampling tube was positioned $30 \mathrm{~cm}$ away from the ARC's nose on the feed bin's right side (Figure 2). The ARC's breath was continuously sampled at the inlet point of the sampling tube at a rate of $4 \mathrm{~L} / \mathrm{min}$ and analyzed by the Fourier transform infrared spectroscopy gas analyzer with one gas concentration value per 2 or $3 \mathrm{~s}$.

The ARC simulated 21 different cows with controlled methane release rates from 200 to $400 \mathrm{~g} / \mathrm{d}$ with increments of $10 \mathrm{~g} / \mathrm{d}$. The tidal volume and breath frequency of each simulated cow were set at $4.4 \mathrm{~L}$ and 30 times per minute, as used in the laboratory tests. When each simulated cow was started, the ARC was running without injecting methane until the breath air had warmed to the desired temperature of $25^{\circ} \mathrm{C}$. Then, each flux level was simulated during $5 \mathrm{~min}$, representing one measurement. These 21 simulated cow methane release rates were tested in random order on one day, with one measurement per half hour, between 0830 to 1900 h. We removed the dummy cow and ARC after and reinstalled before each measurement to enable milking of cows in the milking robot between measurements. Measurements were repeated on $4 \mathrm{~d}$ for 4 consecutive weeks.

During this barn experiment, two 3-dimensional anemometers measured air velocity in the barn and around the milking robot. One was placed at a height of 180 and $55 \mathrm{~cm}$ away from the barn's east wall and the other at a height of $120 \mathrm{~cm}$ next to the dummy 
cow's head. During each measurement, air velocity and direction were measured every second. Air temperature and humidity were also measured every half hour with a sensor (HygroClip S3, Rotronic, Hauppauge, NY) that was placed in the barn at a height of $2 \mathrm{~m}$.

\section{Effect of a Cow's Head Movement}

To analyze the effects of a cow's head movement on the variability of BMC measurements, we first observed the head movement behavior in the feeder in the barn of 20 dairy cows over $2 \mathrm{~d}$ from 0900 to $1600 \mathrm{~h}$ with 10 cows per day. For each cow, we observed the duration of the cow's head in 3 locations (Figure 2): inside in the center of the feed bin (IN-C area), where cows take concentrates during milking; at the right top side of the feed bin close to the sampling point (IN-SP area); and outside the feed bin (OUT area), where cows sniff around. These 3 locations were defined because of different sampling distances between the cow's head and the sampling point. The sampling distance was the shortest in the IN-SP area because the sampling inlet was placed on the feed bin's right side. In the OUT area, the distance was the largest. We assumed that sampling distance and head position influenced the dilution rate of emitted methane from the exhalation point. The variability in head positions between the 20 dairy cows was quantified, as well as the resulting effect on the variability of measured concentrations at sampling point (see the Statistical Analysis and Calculations section for underlying calculations).

\section{Effects of a Cow's Air Exhalation Rate}

To explore and assess the effects of air exhalation rate on measured methane concentrations, we used the concentration pattern prediction model of the ARC ( Wu et al., 2015). This ARC prediction model is a physical flow model that represents the physical structure of the $\mathrm{ARC}$ and the movement of the piston, the varying injected methane flux, and air flow. The prediction model calculates the methane concentration at the nose position in time as a function of the ARC settings. With this model, we predicted for 5 scenarios the effects of variable tidal volume and breath frequency on emitted air's methane concentrations.

In scenario 1 , an air exhalation rate of $132 \mathrm{~L} / \mathrm{min}$ was used, with a tidal volume of $4.4 \mathrm{~L}$ and a breath frequency of 30 times per minute (Wu et al., 2015). This air exhalation rate represents the mean cow exhalation level, and is based on reported literature values of Holstein Friesian cows (Stevens, 1981; Gallivan et al., 1989, 1991). The reported coefficient of variation (CV) of tidal volume between cows in these studies was $15 \%$ and the CV of breath frequency between cows was $16 \%$. Expressed as standard deviations of mean levels, the tidal volume varied $0.6 \mathrm{~L}$ and breath frequency varied 4.9 times per minute from the mean level. These values resulted in an air exhalation rate ranging from 95 to $175 \mathrm{~L} / \mathrm{min}$. The lowest and highest exhalation rates in this range were used in scenario 2 and scenario 3, respectively. Because the reported CV was measured from a small number of cows and may also have included substantial measurement errors, we defined 2 additional scenarios assuming a $5 \%$ variation of tidal volume and breath frequency between cows. We used the mean tidal volume and breath frequency from this type of variation, resulting in an air exhalation rate of $120 \mathrm{~L} / \mathrm{min}$ in scenario 4, and $145 \mathrm{~L} / \mathrm{min}$ in scenario 5 .

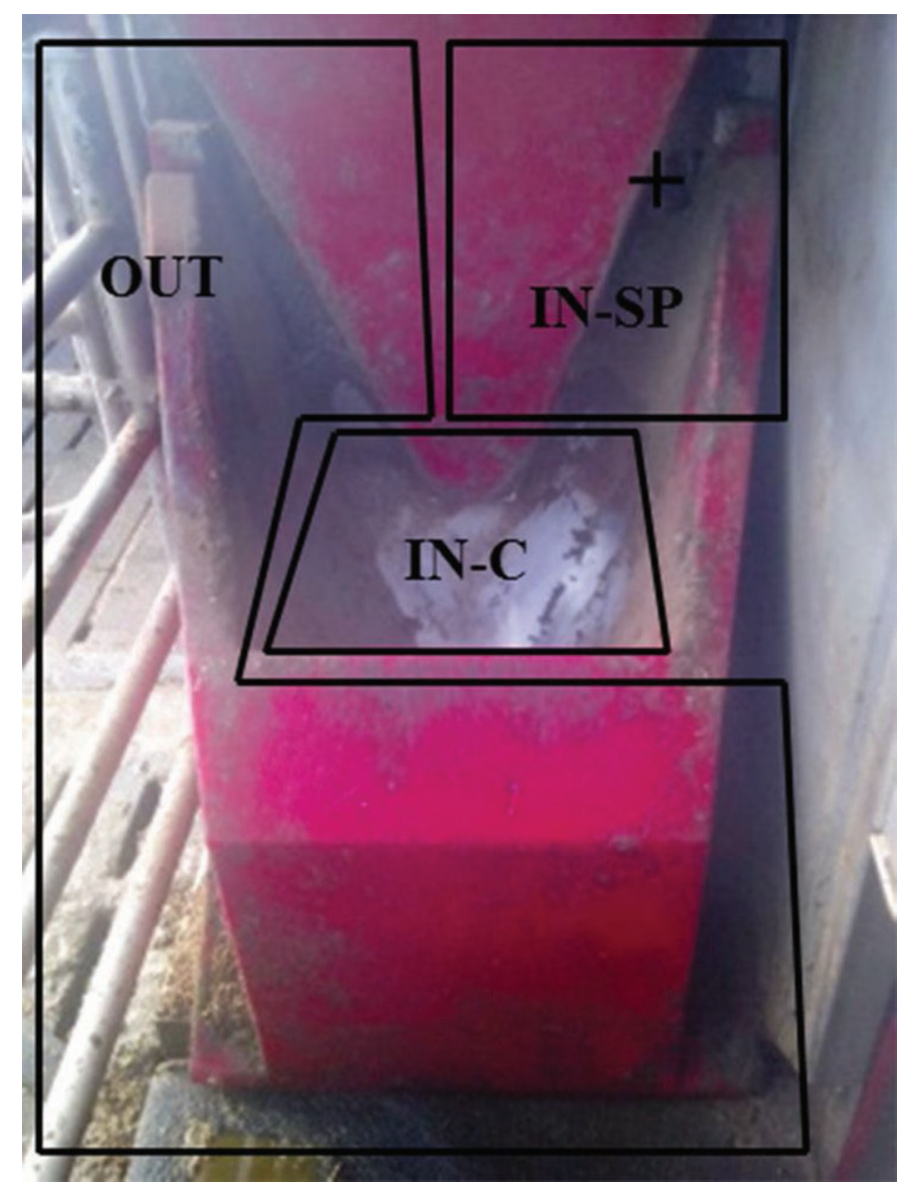

Figure 2. Schematic overview of 3 locations to analyze cow's head movement in and out of the feed bin. IN-C = inside the center of the feed bin where cows take in concentrates during milking; IN-SP = right top area of the feed bin close to the sampling point; and OUT $=$ outside the feed bin where cows sniff around. The + symbol indicates the place of the gas sampling point. Color version available online. 


\section{Statistical Analysis and Calculations}

Data were analyzed by using the GenStat 16 statistical system (VSN International Ltd., Hemel Hempstead, UK). All measured methane concentrations of each simulated cow were corrected for methane background present in the laboratory and in the dairy barn by subtracting the measured background methane concentration. This background methane concentration was measured by the same sampling point in the feed bin and was calculated as the mean of the methane concentration before and after each measurement when the ARC did not release methane.

Experiments in the Laboratory and Barn. The analysis focused on investigating the effects of the imposed ARC methane release rates on the methane concentration at the sampling point $\left(\mathbf{M C}_{\mathbf{S P}}\right)$, the variability of dilution rate of $\mathrm{MC}_{\mathrm{SP}}$ when compared with the reference methane concentration at the ARC's exhalation point $\left(\mathbf{M C}_{\mathbf{E P}}\right)$, and the distinctive power of sampling strategies to demonstrate different methane production between cows.

The relation between $\mathrm{MC}_{\mathrm{SP}}$ (in ppm) and controlled methane release (expressed for convenience of comparison in $\mathrm{g} / \mathrm{d}$ ) was investigated with a linear regression model. Regression slope, $\mathrm{R}^{2}$-value, and residual standard errors were used as evaluation parameters.

The relation between $\mathrm{MC}_{\mathrm{EP}}$ and $\mathrm{MC}_{\mathrm{SP}}$ (both in ppm) was expressed as the captured fraction of methane (CFM) by using the following equation:

$$
\mathrm{CFM}=\frac{\mathrm{MC}_{\mathrm{SP}}}{\mathrm{MC}_{\mathrm{EP}}} .
$$

We calculated $\mathrm{MC}_{\mathrm{EP}}$ as the mean concentration from the prediction model of the ARC during a measurement and investigated the relation between CFM and controlled daily methane release with a linear regression model. The CV of CFM ( $\left.\mathbf{C V}_{\mathbf{C F M}}\right)$ in each laboratory and barn measurement was calculated as follows:

$$
\mathrm{CV}_{\mathrm{CFM}}=\frac{\mathrm{SD}_{\mathrm{CFM}}}{\overline{\mathrm{CFM}}} \times 100,
$$

where $\overline{\mathrm{CFM}}$ is the mean CFM of imposed methane release rates in each measurement, and $\mathrm{SD}_{\mathrm{CFM}}$ is the standard deviation of CFM.

To reach a required level of distinctive power in demonstrating a difference in methane production between cows, we investigated effects of repeated measurements that would meet the required distinctive power level. First, we calculated from the required difference in methane production the associated difference in $\mathrm{MC}_{\mathrm{EP}}$
$\left(\Delta \mathbf{M C}_{\mathrm{EP}}\right)$, making use of the constant exhalation rate of the ARC in our experiments. As a next step, we converted $\Delta \mathrm{MC}_{\mathrm{EP}}$ into a required difference of concentration at sampling point level $\left(\boldsymbol{\Delta} \mathbf{M C}_{\mathrm{SP}}\right)$, by multiplying $\Delta \mathrm{MC}_{\mathrm{EP}}$ with CFM. Determination of $\Delta \mathrm{MC}_{\mathrm{SP}}$ is based on the difference between concentration means of 2 cows. To be significant at $\alpha=0.05$, the required difference between the means $\mathrm{MC}_{\mathrm{EP} 1}$ and $\mathrm{MC}_{\mathrm{EP} 2}$ should fulfill Equation [3]:

$$
\left(\left|\mathrm{MC}_{\mathrm{EP} 1}-\mathrm{MC}_{\mathrm{EP} 2}\right|\right) \times \mathrm{CFM}>\mathrm{tc} \times \sqrt{\mathrm{SEM}_{1}^{2}+\mathrm{SEM}_{2}^{2}},
$$

where tc is the critical t-value depending on the number of measurements (n), which is 1.95 at $\alpha=0.05$ level for $\mathrm{n}=\infty$, and $\mathrm{SEM}_{1}$ and $\mathrm{SEM}_{2}$ represent the standard errors of both cow means. The SEM based on $n$ measurements can be calculated by Equation [4]:

$$
\mathrm{SEM}=\frac{\mathrm{SD}_{\mathrm{CFM}} \times \mathrm{MC}_{\mathrm{EP}}}{\sqrt{\mathrm{n}}},
$$

where SEM is the standard error of the mean measured methane concentrations in $\mathrm{ppm}, \mathrm{MC}_{\mathrm{EP}}$ is a chosen representative concentration level, and $\mathrm{n}$ is the number of measurements. By solving Equations [3] and [4], we can calculate the smallest number of measurements $n$ needed to demonstrate required differences between the methane production rates of 2 cows.

In the barn experiment, mean air velocity was calculated for each measurement. The relation between measured methane concentration and mean air velocity was investigated with a linear regression model.

Effects of a Cow's Head Movement. To assess the effects of a cow's head movement on the variability of CFM values, we used video observations of cows visiting a feed bin in a milking robot. First, we estimated the CFM values for each cow's head location in the feed bin (Figure 2). The CFM linked to the IN-C location was derived from the mean CFM of the barn experiment because the ARC's nose was always at this position in the feed bin. The CFM at the IN-SP location was assumed to be 0.10 higher than the CFM of the IN-C location because the cow's head was closer to the sampling location, thus enabling a higher sampling efficiency by sampling less diluted exhaled air. The CFM of the OUT location was 0 because the cow's head was far away from sampling location. With different duration time and CFM for the different head locations, we calculated the CV of CFM between cows caused by the cows' head movements with the following 2 equations: 


$$
\begin{gathered}
\mathrm{CFMI}_{\mathrm{i}}=\frac{\mathrm{t}_{1 \mathrm{i}}}{\mathrm{T}_{\mathrm{i}}} \times \mathrm{CFM}_{1}+\frac{\mathrm{t}_{2 \mathrm{i}}}{\mathrm{T}_{\mathrm{i}}} \times \mathrm{CFM}_{2}+\frac{\mathrm{t}_{3 \mathrm{i}}}{\mathrm{T}_{\mathrm{i}}} \times \mathrm{CFM}_{3}, \quad[5] \\
\mathrm{CV}_{\text {CFM-head-movement }}=\frac{\mathrm{SD}_{\mathrm{CFMI}}}{\frac{1}{\mathrm{n}} \times \sum_{\mathrm{i}=1}^{\mathrm{n}} \mathrm{CFMI}_{\mathrm{i}}} \times 100 \%, \quad[6]
\end{gathered}
$$

where $\mathrm{CFMI}_{\mathrm{i}}$ is CFM index of each observed cow (i); $t_{1 i}, t_{2 i}$, and $t_{3 i}$ are the duration times that the observed cow (i) spent at the IN-C, IN-SP, and OUT locations, respectively, in seconds; $T_{i}$ is the total duration time that the observed cow (i) spent in the milking robot in seconds; $\mathrm{CFM}_{1}, \mathrm{CFM}_{2}$, and $\mathrm{CFM}_{3}$ are the CFM at the IN-C, IN-SP, and OUT locations, respectively; $\mathrm{n}$ is the number of observed cows, which is 20 in this study; and $\mathrm{SD}_{\mathrm{CFMI}}$ is the standard deviation of the CFMI of all observed cows. After analyzing the CV of CFM caused by head movement, we calculated the total CV of CFM as follows:

$$
\mathrm{CV}_{\mathrm{t}}=\sqrt{\mathrm{CV}_{\mathrm{CMF}-\text { head-movement }}^{2}+\mathrm{CV}_{\text {CMF-barn }}^{2}} .
$$

Effects of a Cow's Air Exhalation Rate. We used the following concentration pattern prediction model of the ARC to assess the effects of air exhalation rate on measured methane concentration.

$$
\int_{0}^{t} x \mathrm{~d} t=\int_{0}^{\mathrm{t}} M \mathrm{~d} t+\int_{0}^{t} C_{e x, \text { in }} \times V \mathrm{~d} t
$$

where $x$ is methane mass accumulation rate in the cylinder in $\mathrm{g} / \mathrm{s} ; M$ is methane mass injection rate by the mass flow controller in $\mathrm{g} / \mathrm{s} ; C_{e x, \text { in }}$ is methane concentration in $\mathrm{g} / \mathrm{L}$, which is emitted air's methane concentrations during exhaling or ambient methane concentration during inhaling; $V$ is gas exchange rate in $\mathrm{L} / \mathrm{s}$, which is a positive value during inhaling and a negative value during exhaling. This prediction model assumes that all gas is completely mixed inside the cylinder, including injected methane. The methane mass accumulation rate is solved in every $0.1 \mathrm{~s}$ time step. During the exhaling period, $C_{e x, \text { in }}$ calculated at $t_{i-1}$ is applied to solve methane mass accumulation rate $x$ at $t_{i}$.

\section{RESULTS AND DISCUSSION}

\section{Laboratory Experiment}

Figure 3a shows the methane concentrations $\left(\mathrm{MC}_{\mathrm{SP}}\right)$ measured at the $5-\mathrm{cm}$ and at the $30-\mathrm{cm}$ sampling distances at controlled methane release rates. For the used range of preset methane release rates (expressed in $\mathrm{g} / \mathrm{d}$ ),
$\mathrm{MC}_{\mathrm{SP}}$ varied from $539 \mathrm{ppm}(\mathrm{SD}, 16.0)$ to $1,030 \mathrm{ppm}$ $(\mathrm{SD}, 28)$ at the $5-\mathrm{cm}$ sampling distances, and $543 \mathrm{ppm}$ $(\mathrm{SD}, 33)$ to $1,100 \mathrm{ppm}(\mathrm{SD}, 92)$ at the 30-cm sampling distances. Both series of $\mathrm{MC}_{\mathrm{SP}}$ at these 2 sampling distances were strongly linearly related to the controlled methane release rate $\left(\mathrm{R}^{2}=0.97\right.$ and $\left.0.84, P<0.001\right)$. During the experiment, mean air velocity was $0.04 \mathrm{~m} / \mathrm{s}$ (SD, 0.01). Although aerial conditions were stable in the laboratory, the CFM was 0.60 (SD, 0.03) at the 5 -cm sampling distances and $0.62(\mathrm{SD}, 0.05)$ at the 30-cm sampling distances (Figure $3 \mathrm{~b}$ ), which was comparable (0.70) to the study of Huhtanen et al. (2015). Emitted methane reaching the sampling point inlet was already considerably diluted compared with the methane concentrations at exhalation point $\left(\mathrm{MC}_{\mathrm{EP}}\right)$. In contrast to the measured concentrations, the CFM at these 2 sampling distances were not influenced by the controlled methane release; the slope of the regression lines at these 2 sampling distances did not differ from zero $(P>0.05)$. The CFM did not differ between the 2 sampling distances $(P>0.05)$. This means that at a source-sampling distance of $30 \mathrm{~cm}$ measured methane concentrations are similar to those measured at 5 -cm sampling distance from the cow's nose under laboratory conditions. However, measurement variations in CFM at the $30-\mathrm{cm}$ sampling distances $(8.8 \%)$ were higher than those at 5 -cm sampling distances (5.0\%), and much smaller than the variability $(23 \%)$ observed by Huhtanen et al. (2015). These variations were mainly caused by the movement of air released by the ARC, as aerial conditions were relatively stable in the laboratory. Released air dispersed in and around the feed bin and diluted into the environment. The methane concentration at a larger sampling distance varied probably more because of less direct influence from the source. Huhtanen et al. (2015) observed larger variations in CFM at $30-\mathrm{cm}$ sampling distances $(23 \%)$ with a smaller exhalation rate $(111 \mathrm{~L} / \mathrm{min}$ compared with $132 \mathrm{~L} / \mathrm{min}$ in this study). A smaller exhalation rate probably means that exhaled air is easier affected by surrounding air flow patterns resulting in a larger variation in the CFM.

The standard error of a measurement was $37 \mathrm{ppm}$ at the $5-\mathrm{cm}$ and $75 \mathrm{ppm}$ at the $30-\mathrm{cm}$ sampling distance. Consequently, the measurement $\mathrm{CV}$ of mean measured methane concentrations amounted to $4.8 \%$ at the $5-\mathrm{cm}$ and $9.3 \%$ at the $30-\mathrm{cm}$ sampling distance. These measurement CV under stable laboratory conditions were smaller than the $\mathrm{CV}$ of methane production between-cows measured in respiration chambers (7-17\%) (Blaxter and Clapperton, 1965; Yan et al., 2010). In principle, these measurement errors can be reduced by repeating measurements. To demonstrate a difference of $50 \mathrm{~g} / \mathrm{d}$ in methane production between 
Table 1. The SE of a measurement, CV of captured fraction of methane (CFM), and required number of measurements to demonstrate a difference in methane production between 2 cows of 30 and $50 \mathrm{~g} / \mathrm{d}$ (at a production level of $300 \mathrm{~g} / \mathrm{d}$ ), under 4 sampling conditions

\begin{tabular}{|c|c|c|c|c|}
\hline \multirow[b]{2}{*}{ Sampling conditions } & \multirow{2}{*}{$\begin{array}{c}\mathrm{SE} \\
(\mathrm{ppm})\end{array}$} & \multirow{2}{*}{$\begin{array}{c}\text { CV of CFM } \\
(\%)\end{array}$} & \multicolumn{2}{|c|}{$\begin{array}{l}\text { Required no. } \\
\text { of measurements }\end{array}$} \\
\hline & & & $30 \mathrm{~g} / \mathrm{d}$ & $50 \mathrm{~g} / \mathrm{d}$ \\
\hline Laboratory + 5-cm sampling distance & 37 & 5.0 & 3 & 1 \\
\hline Laboratory $+30-\mathrm{cm}$ sampling distance & 75 & 8.8 & 7 & 3 \\
\hline Barn + 30-cm sampling distance & 86 & 21.8 & 38 & 15 \\
\hline Barn +30 -cm sampling distance + head movements & 94 & 24.8 & 53 & 21 \\
\hline
\end{tabular}

cows producing around $300 \mathrm{~g} / \mathrm{d}$, the minimum number of measurements would amount to 1 at the 5 -cm sampling distances and 3 at the $30-\mathrm{cm}$ sampling distances (Table 1). However, to demonstrate a $30 \mathrm{~g} / \mathrm{d}$ difference between cows producing around $300 \mathrm{~g} / \mathrm{d}$, the minimum number of measurements would increase to 3 at the

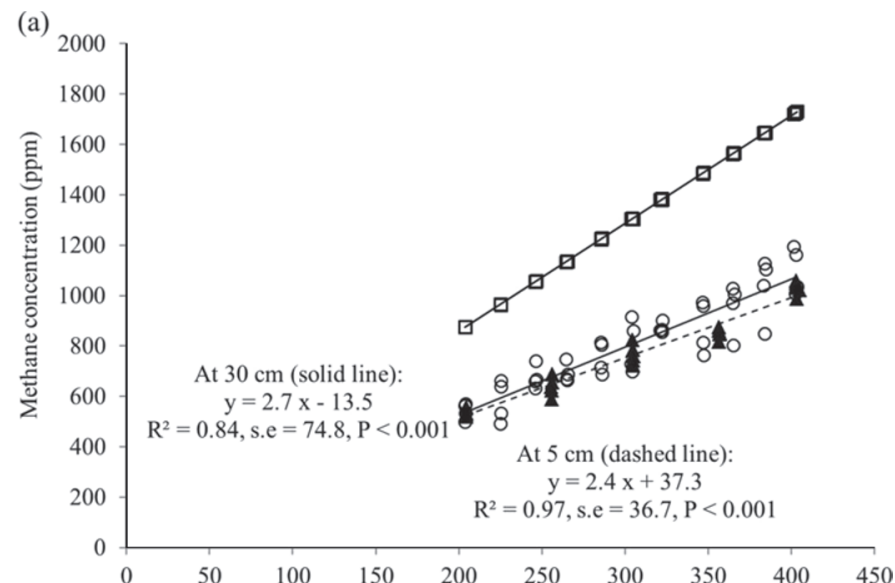

(b)

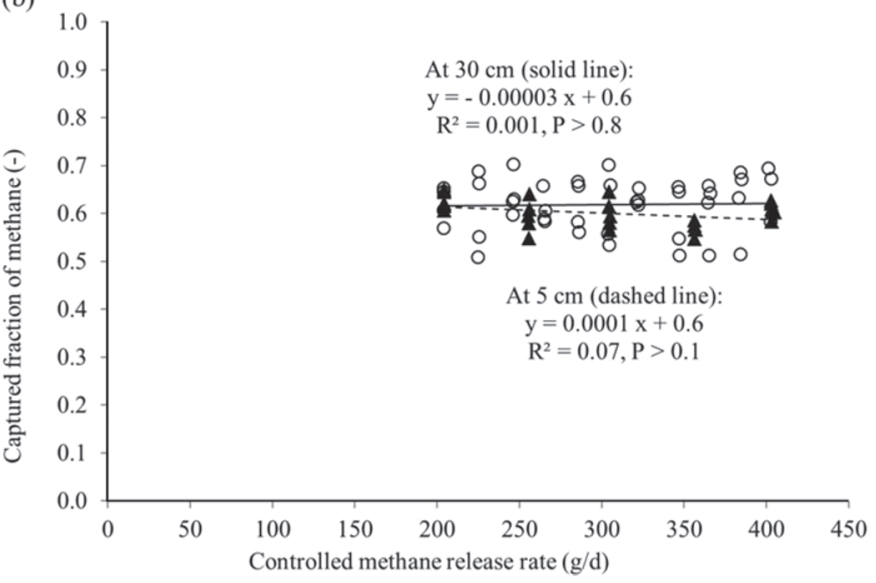

Figure 3. Methane concentrations at the exhalation point $(\square)$ and measured concentrations at a sampling distance of $5 \mathrm{~cm}(\mathbf{\Lambda} ; \mathrm{n}=25)$ and $30 \mathrm{~cm}(\mathrm{O} ; \mathrm{n}=44 ; \mathrm{a})$, and captured fraction of methane (b) versus controlled methane release rate in the laboratory. Methane concentrations at the exhalation point $(\square)$ are predicted mean methane concentrations of the artificial reference cow's emitted air. 5-cm sampling distance and 7 at the 30 -cm sampling distance (Table 1). Based on an average of 2 visits to the milking robot per cow per day, the minimum number of measurement days is 1.5 for the 5 -cm sampling distance and 3.5 for the $30-\mathrm{cm}$ sampling distance.

\section{Barn Experiment}

Airflow Effects. Table 2 shows the environmental data and CFM of the 4 measurement days, and the differences in climatic conditions between days, especially for air velocity. Air velocity measured at the barn's east wall varied from 0.64 to $1.33 \mathrm{~m} / \mathrm{s}$. This range is consistent with other studies (Wu et al., 2012; Kaharabata et al., 2000). Inside the barn, air velocity decreased to 0.09 to $0.24 \mathrm{~m} / \mathrm{s}$ around the feed bin of the milking robot. This air velocity was measured at a height of $120 \mathrm{~cm}$ in the cows' active zone. In this zone, $\mathrm{Wu}$ et al. (2015) measured a similar range of air velocity around lying cubicles in a cow barn. Captured fraction of methane was negatively related to the air velocity around the feed bin $(P<0.001 ;$ Figure 4$)$. With a higher air velocity, emitted methane is more diluted before it is sampled at the sampling point. The highest mean CFM was 0.35 on the second measurement day and the lowest was 0.26 on the third measurement day. These values corresponded with the lowest and highest daily mean air velocity measured. With a higher induced air velocity $(6 \mathrm{~m} / \mathrm{s})$ under laboratory conditions, the CFM can even decrease to 0.13 (Huhtanen et al., 2015). Garnsworthy et al. (2012) released a known concentration of $\mathrm{CO}_{2}$ gas to estimate dilution rate in the barn. However, without considering the effects of cows' exhalation process on the distribution and dilution of emitted gases, this procedure may end up in biased estimates of the methane production rate.

\section{Methane Concentration Versus Methane} Flux. Measured methane concentrations at the $30-\mathrm{cm}$ sampling distances were linearly related to controlled methane release under barn conditions $(P<0.001)$, but with higher variations than under laboratory conditions (Figure 5a). Similar to the laboratory findings, 
Table 2. Environmental data and mean captured fraction of methane (with SD) on 4 measurement days in the barn

\begin{tabular}{|c|c|c|c|c|}
\hline \multirow[b]{2}{*}{ Item } & \multicolumn{4}{|c|}{ Measurement day } \\
\hline & 1 & 2 & 3 & 4 \\
\hline Temperature $\left({ }^{\circ} \mathrm{C}\right)$ & $22.7(2.0)$ & $18.7(2.1)$ & $17.0(0.9)$ & $21.2(2.2)$ \\
\hline Relative humidity (\%) & $66.0(7.0)$ & $55.2(3.6)$ & $75.7(7.7)$ & $61.7(7.7)$ \\
\hline Air pressure $(\mathrm{Pa})$ & $102.4(0.3)$ & $102.3(0.2)$ & $100.9(1.1)$ & $101.8(0.5)$ \\
\hline \multicolumn{5}{|l|}{ Air velocity $(\mathrm{m} / \mathrm{s})$} \\
\hline At the east side wall & $0.82(0.27)$ & $0.64(0.17)$ & $1.33(0.29)$ & $0.80(0.33)$ \\
\hline Around the feed bin & $0.12(0.04)$ & $0.09(0.03)$ & $0.24(0.05)$ & $0.10(0.04)$ \\
\hline Captured fraction of methane & $0.30(0.05)$ & $0.35(0.06)$ & $0.26(0.07)$ & $0.33(0.05)$ \\
\hline
\end{tabular}

CFM were not influenced by controlled methane release rate in the barn (Figure 5b; the slope of the regression lines did not differ from zero $(P>0.05))$. Due to the more disturbing aerial conditions, the mean CFM decreased from 0.62 at the 30 -cm sampling distances in the laboratory to 0.31 in the barn (Figure 5b).

The standard error of measurement increased from $75 \mathrm{ppm}$ at the $30-\mathrm{cm}$ sampling distances in the laboratory to $86 \mathrm{ppm}$ in the barn. The measurement $\mathrm{CV}$ of the mean measured methane concentration subsequently increased to $21.8 \%$. With a lower CFM and a higher measurement error, differences of measured methane concentrations under barn conditions were smaller and varied more between simulated cows than in the laboratory, which means more measurements are required to demonstrate differences between cows under barn conditions. To distinguish a difference of 50 $\mathrm{g} / \mathrm{d}$ between cows around a methane production of 300 $\mathrm{g} / \mathrm{d}$, the minimum number of measurements must be increased from 3 in the laboratory to 15 in the barn. If we want to demonstrate a difference of $30 \mathrm{~g} / \mathrm{d}$ between cows around a methane production of $300 \mathrm{~g} / \mathrm{d}$ in the

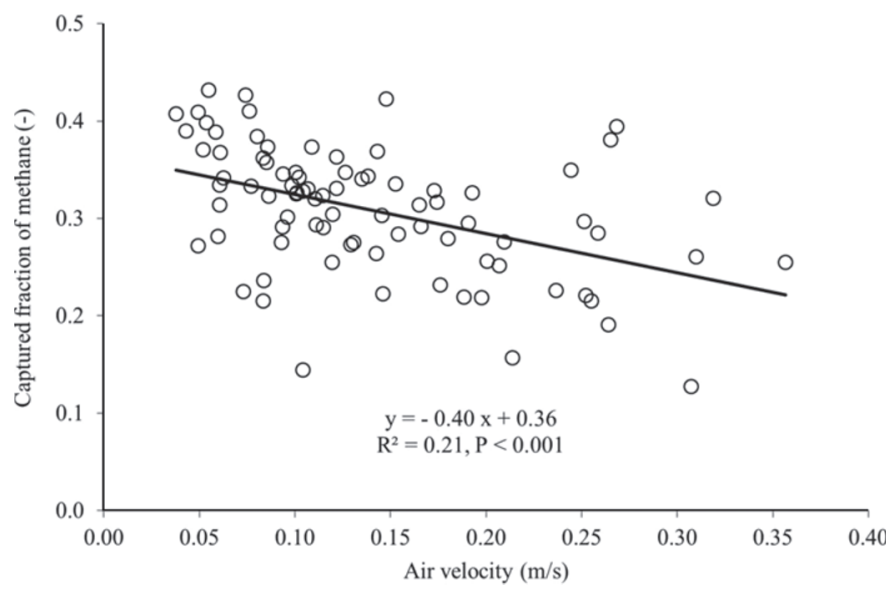

Figure 4. Relation between captured fraction of methane and air velocity near the feed bin in the barn for simulated methane released rates ranging between 200 and $400 \mathrm{~g} / \mathrm{d}(\mathrm{n}=84)$. barn, the minimum number of measurements must be increased to 38 (Table 1). Considering an average of 2 visits to the milking robot per cow per day, minimum measurement days are 7.5 for $50 \mathrm{~g} / \mathrm{d}$ and 19 for 30 $\mathrm{g} / \mathrm{d}$ methane production differences. It is noted that we

(a)

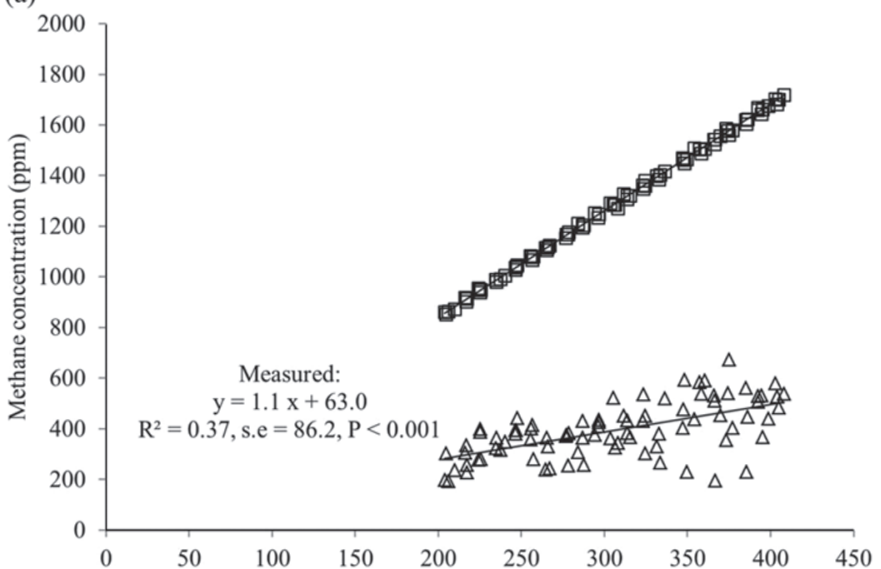

(b)

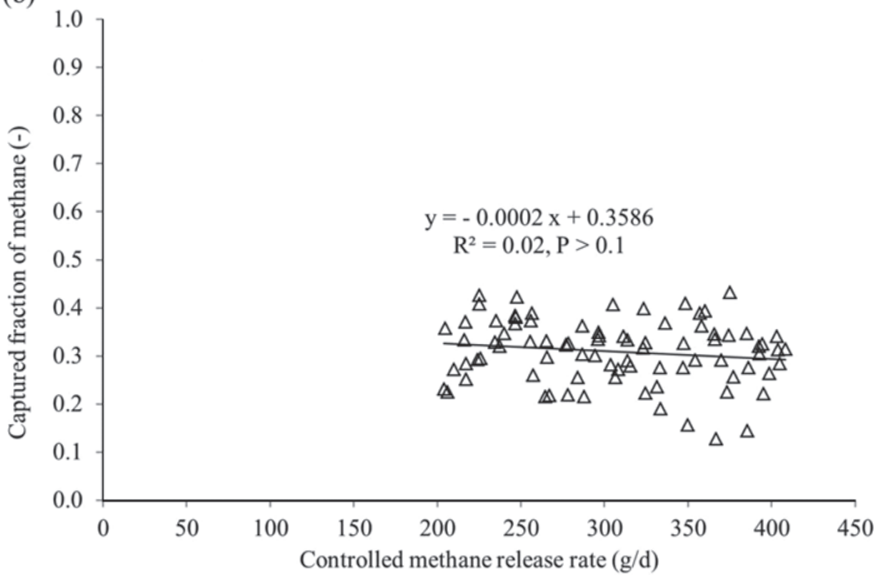

Figure 5. Methane concentrations at the exhalation point $(\square)$ and measured concentrations at a sampling distance of $30 \mathrm{~cm}(\Delta ; \mathrm{n}=84$ a), and captured fraction of methane (b) versus controlled methane release rate in the barn. Methane concentrations at the exhalation point $(\square)$ are predicted mean methane concentrations of the artificial reference cow's emitted air. 
have ignored the circadian pattern of methane production rate (Cottle et al., 2015) and other within-animal variation in methane production related to feed intake and physiological status, in analyzing required measurement number. As a short-term measurement technique, the BMC measurement would require a higher number of measurements to compensate for these sources of variation.

Effects of a Cow's Head Movement. During the experiment in the barn, the ARC's nose was placed in the feed bin where a cow would normally place its mouth. However, cows are free to move their head in the bin during the visit to the milking robot, and consequently will create variability in sampling distance. According to the records of the 20 observed cows, cows spent $366 \mathrm{~s}(\mathrm{SD}, 84)$ in the milking robot during each visit. In each visit, the cow's head was located at the IN-C during $76 \%$ (SD, 13), OUT during 16\% (SD, 10), and IN-SP during $8 \%(\mathrm{SD}, 10)$ of the total visit time. The CFM was estimated as 0.31 at the IN-C as measured from the ARC in the barn, 0.41 at the IN-SP as being closest to the sampling tube, and 0 in the area outside the feed bin (OUT area). Based on these values, the CFM's CV caused by head movement was estimated at 13\% (Equation [6]). Combining this estimated head movement with the measured $\mathrm{CV}$ in the barn with a fixed head position, the total CFM's CV increased to 25\% (Equation [7]). The assumed CFM at IN-SP is uncertain, but the total CFM's CV appeared to be rather insensitive to the assumed CFM at IN-SP; if the assumed CFM at IN-SP changes by $10 \%$, the total CFM's CV only varies $1.6 \%$. Therefore, the total CFM's CV of $25 \%$ is a relatively robust representation of the effects of a cow's head movement. With this CV, the minimum measurement number is 21 to demonstrate a difference of $50 \mathrm{~g} / \mathrm{d}$ between cows around a methane production of $300 \mathrm{~g} / \mathrm{d}$. Without head movement effects, the minimum number of measurements is 15 (Table 1). To demonstrate a $30 \mathrm{~g} / \mathrm{d}$ difference between cows around $300 \mathrm{~g} / \mathrm{d}$, minimum measurement number must be increased to 53 , which is equal to 26.5 measurement days. Two ways are used to overcome the variations of the CFM caused by cows' head movement: one is to filter data by eliminating values where the methane eructation peak is below a defined baseline value (Garnsworthy et al., 2012); the second one is applying a head position sensor as in the GreenFeed system to only analyze the results when the cows' head is in the IN-C area (Huhtanen et al., 2015). The first one needs a precise definition of the baseline and may bias results by eliminating low eructation peaks from correctly positioned animals. The second one is a better solution, but requires sensors to be installed in the feed bin, in the milking robot, and attached to the cow.
If we consider the CFM's CV only changed from 21.8 to $24.8 \%$ with cows' head movement effects, applying more measurement would be a simple, feasible, and economical solution.

Effects of the Air Exhalation Rate. Different tidal volumes and breath frequencies will result in various air exhalation rates between cows. Predicted methane concentrations at the exhalation point $\left(\mathrm{MC}_{\mathrm{EP}}\right)$ with 4 different air exhalation rates (scenario 2-5) are compared with the mean air exhalation rate (scenario 1) in Figure 6. A higher air exhalation rate decreases $\mathrm{MC}_{\mathrm{EP}}$. Compared with scenario 1, the emitted air's methane concentrations are $33 \%$ higher in scenario 2 with the lowest air exhalation rate, and $26 \%$ lower in scenario 3 with the highest air exhalation rate. The air exhalation rates in scenario 4 and 5 are closer to the mean level in scenario 1, consequently the emitted air's methane concentrations are only $12 \%$ higher (scenario 4) and $8 \%$ lower (scenario 5) as compared with scenario 1. Due to the variations in the air exhalation rate between cows, the relation between emitted air's methane concentration level $\left(\mathrm{MC}_{\mathrm{EP}}\right)$ and methane release rate is disturbed. For instance, an emitted air's methane concentration level of $1,200 \mathrm{ppm}$ may indicate a methane release of $213 \mathrm{~g} / \mathrm{d}$ in scenario $2,255 \mathrm{~g} / \mathrm{d}$ in scenario 4 , $285 \mathrm{~g} / \mathrm{d}$ in scenario $1,310 \mathrm{~g} / \mathrm{d}$ in scenario 5 , and 385 $\mathrm{g} / \mathrm{d}$ in scenario 3 (Figure 6 ).

Measurement Errors of the Breath Methane Concentration Measurement. The measurement results in this study showed that measured methane concentration is affected by surrounding air flow patterns, sampling distances, and cows' head movement. Both Garnsworthy et al. (2012) and Bell et al. (2014)

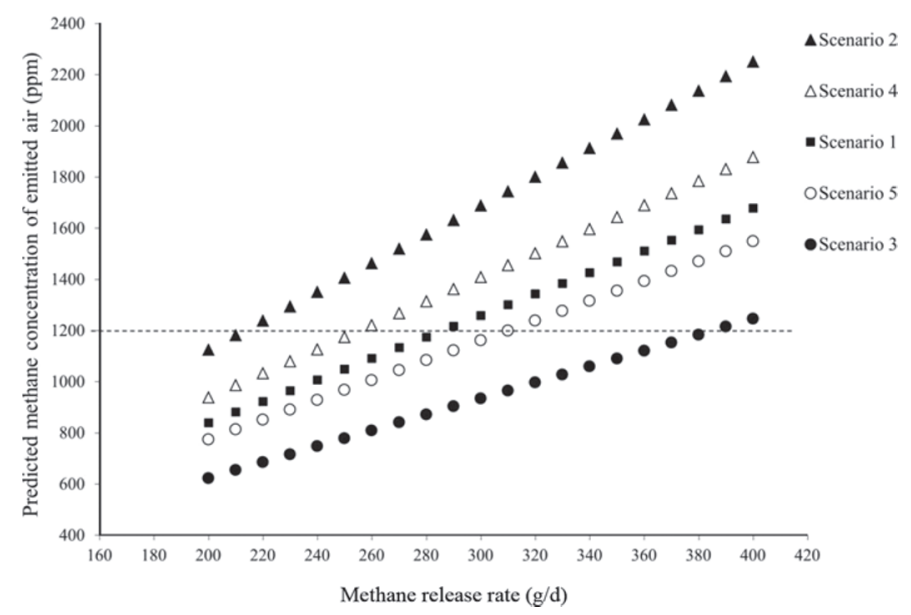

Figure 6. Predicted methane concentrations at the exhalation point as a function of methane release rate under 5 scenarios with different air exhalation rates. The air exhalation rate is $132 \mathrm{~L} / \mathrm{min}$ in scenario $1(\mathbb{\square}), 95 \mathrm{~L} / \mathrm{min}$ in scenario $2(\boldsymbol{\Delta}), 175 \mathrm{~L} / \mathrm{min}$ in scenario 3 $(\bullet), 120 \mathrm{~L} / \mathrm{min}$ in scenario $4(\Delta)$, and $145 \mathrm{~L} / \mathrm{min}$ in scenario $5(\mathrm{O})$. 
reported a much bigger variation of methane production between cows when using the BMC method than when using the respiration chamber. Measurement errors of the BMC measurement include (1) random errors caused by aerial conditions, and variable sourcesampling distances by head movements; and (2) systematic errors at cow level caused by variations in the air exhalation rates between cows, and at barn level where air flow patterns around measurements points may vary as a result of differences in ventilation management, barn layout, and geographical location. The standard random error of a measurement increased from $37 \mathrm{ppm}$ in the laboratory with the 5 -cm sampling distance to $94 \mathrm{ppm}$ in the barn with the 30-cm sampling distance and head movements (Table 1). These random errors influence the precision of measured methane production while using the BMC measurement. These random errors can be reduced by repeating measurements. To assess feeding effects on methane production, random errors should be reduced to demonstrate the difference between cows. To demonstrate a certain level of difference between cows in methane production, Table 1 shows the required number of measurements to reduce the effects of random error under barn conditions. It is noted that we ignore in this comparison the effects of within-cow variability in methane production as a result of physiological factors that change in time, and as such are representing a best-case scenario with regard to required number of measurements to test feeding effects. When considering the BMC method for the purpose of breeding cows with lower methane production, the positive correlation between measured methane concentrations and methane production rates will, if applied at sufficient numbers, support genetic progress. For instance, to demonstrate a difference in methane production between 2 cows of $30 \mathrm{~g} / \mathrm{d}$ (at a production level of $300 \mathrm{~g} / \mathrm{d}$ ) at the $30-\mathrm{cm}$ sampling point, 53 measurements are required to reduce the effects of the CFM's CV (24.8\%) in the barn.

Unlike random errors, systematic errors cannot be compensated by repeating measurements. Due to the variations in air exhalation rates between cows, a certain methane production rate will result in systematically different measured methane concentration levels. Variability in air exhalation rate may be the result of genetic differences, but also the result of their physiological status, such as heat stress of high-yielding animals. The risk exists that the efficiency of breeding on this proxy for methane production is undermined by selection on other physiological variables that are correlated with methane concentration in exhaled breath air. To which extent other animal-linked variables are correlated with methane concentration is not clear from the existing literature. The effects of systematic differ- ences in ventilation management and barn layout, will complicate as well interpretation of cow measurements carried out at different barn locations. Our results showed clear effects of air velocity around sampling location on the dilution of emitted methane from the ARC. Consistency in dilution levels between sampling locations in different barns has to be verified before they can be used together. Considering this, the capability of BMC methods is uncertain to assess feeding effects or to select cows for breeding, and requires further investigation into variation sources with a systematic nature.

\section{CONCLUSIONS}

The BMC method is a novel and low-cost on-farm technique. The present results show that measured methane concentrations are positively related to the controlled methane released rates by the ARC under both laboratory and barn conditions. However, disturbed aerial conditions in the barn and head movements of cows increase measurement errors of measured methane concentrations. With these measurement errors, a large number of measurements are required to demonstrate differences in methane production rates between cows. Systematic errors, such as between-cow variation in air exhalation rates, ventilation management, and barn lay-out cannot be reduced by repeated sampling. We conclude that the capability of the BMC method to adequately evaluate and rank methane production rates among cows is highly uncertain and requires further investigation into variation sources with a systematic nature.

\section{ACKNOWLEDGMENTS}

This study was funded by Wageningen Livestock Research, the Ministry of Economic Affairs of the Netherlands (Research Program Sustainable Agriculture, KB-12-006.03-002), and the China Scholarship Council. The authors are grateful to Johan Ploegaert of Wageningen Livestock Research, and Cornelis Cnossen of Wageningen University Farm Technology Group for helping with the experiment in the dairy cow barn (Lelystad, the Netherlands). This work is part of the contents of the first author Liansun Wu's PhD thesis. A small part of it was presented at the European Federation of Animal Science (EAAP) conference in Warsaw, August 31 to September 4, 2015.

\section{REFERENCES}

Bell, M. J., N. Saunders, R. H. Wilcox, E. M. Homer, J. R. Goodman, J. Craigon, and P. C. Garnsworthy. 2014. Methane emissions 
among individual dairy cows during milking quantified by eructation peaks or ratio with carbon dioxide. J. Dairy Sci. 97:6536-6546.

Blaxter, K. L., and J. L. Clapperton. 1965. Prediction of the amount of methane produced by ruminants. Br. J. Nutr. 19:511-522.

Cottle, D. J., J. V. Nolan, and S. G. Wiedemann. 2011. Ruminant enteric methane mitigation: A review. Anim. Prod. Sci. 51:491-514.

Cottle, D. J., J. Velazco, R. S. Hegarty, and D. G. Mayer. 2015. Estimating daily methane production in individual cattle with irregular feed intake patterns from short-term methane emission measurements. Animal 9:1949-1957.

Gallivan, G. J., W. N. McDonell, and J. B. Forrest. 1989. Comparative ventilation and gas exchange in the horse and the cow. Res. Vet. Sci. 46:331-336.

Gallivan, G. J., L. Viel, J. D. Baird, and W. N. McDonell. 1991 Pulmonary structure and function in adult dairy cows with an expanded lung field. Can. J. Vet. Res. 55:15-20.

Garnsworthy, P. C., J. Craigon, J. H. Hernandez-Medrano, and N. Saunders. 2012. On-farm methane measurements during milking correlate with total methane production by individual dairy cows. J. Dairy Sci. 95:3166-3180.

Gerber, P. J., H. Steinfeld, B. Henderson, A. Mottet, C. Opio, J. Dijkman, A. Falcucci, and G. Tempio. 2013. Tackling climate change through livestock-A global assessment of emissions and mitigation opportunities. FAO, Rome, Italy.

Huhtanen, P., E. H. Cabezas-Garcia, S. Utsumi, and S. Zimmerman. 2015. Comparison of methods to determine methane emissions from dairy cows in farm conditions. J. Dairy Sci. 98:3394-3409.

Joo, H. S., P. M. Ndegwa, A. J. Heber, J. Q. Ni, B. W. Bogan, J. C. Ramirez-Dorronsoro, and E. Cortus. 2015. Greenhouse gas emis- sions from naturally ventilated freestall dairy barns. Atmos. Environ. 102:384-392.

Kaharabata, S. K., P. H. Schuepp, and R. L. Desjardins. 2000. Estimating methane emissions from dairy cattle housed in a barn and feedlot using an atmospheric tracer. Environ. Sci. Technol. 34:3296-3302.

Lassen, J., P. Løvendahl, and J. Madsen. 2012. Accuracy of noninvasive breath methane measurements using Fourier transform infrared methods on individual cows. J. Dairy Sci. 95:890-898.

Stevens, D. G. 1981. A model of respiratory vapor loss in Holstein dairy cattle. Trans. ASABE 24:151-154.

Wu, L., P. W. G. Groot Koerkamp, and N. W. M. Ogink. 2015. Design and test of an artificial reference cow to simulate methane release through exhalation. Biosyst. Eng. 136:39-50.

Wu, L., P. W. G. Groot Koerkamp, and N. W. M. Ogink. 2016. Temporal and spatial variation of $\mathrm{CH}_{4}$ and $\mathrm{CO}_{2}$ concentrations in and around lying cubicles of dairy barns. Biosyst. Eng. 151:464-478.

Wu, W., G. Zhang, and P. Kai. 2012. Ammonia and methane emissions from two naturally ventilated dairy cattle buildings and the influence of climatic factors on ammonia emissions. Atmos. Environ. $61: 232-243$.

Yan, T., C. S. Mayne, F. G. Gordon, M. G. Porter, R. E. Agnew, D. C. Patterson, C. P. Ferris, and D. J. Kilpatrick. 2010. Mitigation of enteric methane emissions through improving efficiency of energy utilization and productivity in lactating dairy cows. J. Dairy Sci 93:2630-2638 